\title{
Acute Hypotensive, Diuretic and Antioxidant Activities Induced by Urtica circularis
}

\author{
A. Rodríguez Basso ${ }^{1}$, C. Marrassini ${ }^{2}$, C. Anesini ${ }^{2}$ and S. Gorzalczany ${ }^{1^{*}}$ \\ ${ }^{1}$ Department of Pharmacology, Universidad de Buenos Aires, Facultad de Farmacia y Bioquímica, \\ Junín $9565^{\text {th }}$ Floor, Ciudad Autónoma de Buenos Aires, Argentina. \\ ${ }^{2}$ Department of Pharmacology, Universidad de Buenos Aires, Facultad de Farmacia y Bioquímica, \\ Junín $9562^{\text {nd }}$ Floor, Ciudad Autónoma de Buenos Aires, Argentina.
}

Authors' contributions

This work was carried out in collaboration between all authors. Authors ARB and SG designed the study, performed the statistical analysis, wrote the protocol and wrote the first draft of the manuscript.

Author SG managed the analyses of the study and authors CA and CM the literature searches. All authors read and approved the final manuscript.

Article Information

DOI: $10.9734 / E J M P / 2016 / 25661$

Editor(s):

(1) Marcello Iriti, Professor of Plant Biology and Pathology, Department of Agricultural and Environmental Sciences, Milan State University, Italy.

Reviewers:

(1) Mohammad Jamshed Ahmad Siddiqui, International Islamic University Malaysia, Malaysia.

(2) N. J. Kadima, University of Rwanda, Rwanda.

(3) Enyinnaya Anthony Ogbonnaya, University of Port Harcourt, Nigeria. Complete Peer review History: http://sciencedomain.org/review-history/14180

Original Research Article

Received 14 ${ }^{\text {th }}$ March 2016

Accepted $5^{\text {th }}$ April 2016

Published $15^{\text {th }}$ April 2016

ABSTRACT

Aims: The aim of this study was to investigate the possible hypotensive and diuretic effects of ethanolic extract of Urtica circularis (Hicken) Sorarú (Urticaceae) using preclinical methods.

Place and Duration of Study: Department of Pharmacology, School of Pharmacy and Biochemistry, Universidad de Buenos Aires, from July 2015 to January 2016.

Methodology: Effect on blood pressure and heart rate on anaesthetized normotensive and hypertensive rats were measured using Statham Gould P23ID pressure transducer coupled to a Grass 79D polygraph. Rats were placed in metabolic cages in order to collect urine. Urinary volume was measured and sodium and potassium concentration was estimated from each urine sample using indirect ion-selective electrode potentiometry. The vasorelaxant activity of major compound was studied using isolated aortic rings. Antioxidant activity was estimated measuring 2,2 diphenyl 2 picryl hydrazyl hydrate radical scavenging activity.

Results: The intravenous administration of the extract of $U$. circularis $(0.1-30 \mathrm{mg} / \mathrm{kg})$ in 
anaesthetized normotensive and hypertensive rats caused a dose-dependent reduction in the mean arterial pressure without affecting the heart rate. The greater reduction of blood pressure induced by $U$. circularis was observed in hypertensive rats $(30 \mathrm{mg} / \mathrm{kg}$ : Spontaneously Hypertensive Rat: $-34.7 \pm 3.3 \mathrm{mmHg}$, Spague Dawley: $-18.3 \pm 3.9 \mathrm{mmHg}$ ). Cumulative urinary excretions $24 \mathrm{~h}$ after treatment with the extract 100 and $300 \mathrm{mg} / \mathrm{kg}$ were $18.2 \pm 1.2$ and $14.9 \pm 1.5 \mathrm{~mL}$ respectively, significantly higher than the control group $(9.0 \pm 1.3 \mathrm{~mL})$. The addition of cumulative concentrations of vicenin-2 $\left(10^{-7}-10^{-4} \mathrm{M}\right)$ generated relaxation in endothelium-intact aortic rings pre-contracted with $10^{-7} \mathrm{M}$ Phenylephrine $\left(\mathrm{E}_{\max }=66.2 \pm 3.5 \%\right.$ ). Extract showed antioxidant activity reaching $45 \%$ of DPPH scavenging activity at $1000 \mu \mathrm{g} / \mathrm{mL}$, meanwhile the flavonoid reached $20 \%$ of scavenger capacity.

Conclusion: $U$. circularis, has a diuretic, antioxidant and hypotensive effect. Vicenin-2, the major component of this extract showed vasorelaxant activity, potentially responsible for the properties of the extract.

Keywords: Hypotensive; diuretic; vasorelaxant; antioxidant; Urtica circularis; vicenin-2.

\section{INTRODUCTION}

Hypertension, also known as high or raised blood pressure, is a global public health issue. Complications of hypertension account for 9.4 million deaths worldwide every year. Hypertension is defined as a systolic blood pressure equal to or above $140 \mathrm{~mm} \mathrm{Hg}$ and/or diastolic blood pressure equal to or above $90 \mathrm{~mm}$ $\mathrm{Hg}$. Normal levels of both systolic and diastolic blood pressure are particularly important for the efficient function of vital organs such as the heart, brain and kidneys and for overall health and wellbeing. The higher the blood pressure, the higher the likelihood of harmful consequences to the heart and blood vessels in major organs such as the brain and kidneys. This is known as cardiovascular risk, and can also be high in people with mild hypertension in combination with other risk factors e.g., tobacco use, physical inactivity, unhealthy diet, obesity, diabetes, high cholesterol, low socioeconomic status and family history of hypertension [1].

The renewed interest in the search for new drugs from natural sources, especially from plant sources, has gained global attention during the last two decades. This attention is primarily due to the rich biodiversity, which promises a high diversity of chemicals with the potential novel structures and promising effects. However, of this rich biodiversity, only a small portion has been studied for its medicinal potential. Thus, natural plants and herbs can be our source of drugs, with fewer side effects and better bioavailability for treatment of hypertension in future [2].

Urtica circularis (Hicken) Sorarú (Urticaceae) is an Argentinean native herb also distributed in
Paraguay, Uruguay, and Brazil [3-5]. It is known with the common names of "ortiga", "ortiga crespa", "caá poropí", and "urtiginha miúda" $[3,6]$. Extracts of this plant are popularly used in Argentina because of their diuretic and hypotensive effects and as a potion to lose weight [4]. It is also used as anti-inflammatory agent and against muscular pain [6]. Besides, it is employed for fertility, against hepatic problems, diarrhea, and to avoid hair loss [4]. In addition to its medicinal use, the plant is edible and considered to be highly nutritious for its minerals and vitamins content and it is usually included in different food preparations [4]. Previously, our group reported its antiinflammatory [7] and antinociceptive effects [8], and its activity in central nervous system [9]. No studies are available for its effects on blood pressure.

Several species of Urtica genus are used for different conditions. Among them, the dried roots and rhizomes of Urtica dioica L. and Urtica urens L. are recommended by the World Health Organization for symptomatic treatment of lower urinary tract disorders (nocturia, polyuria, urinary retention) resulting from benign prostatic hyperplasia [1]. The aerial parts are used traditionally to increase the amount of urine to achieve flushing of the urinary tract as an adjuvant in minor urinary complaints [10] and as irrigation therapy for inflammatory diseases of the lower urinary tract and prevention and treatment of kidney gravel [11].

Since other species such as $U$. dioica showed hypotensive and diuretic effects in preclinical models $[12,13]$ and taking into account some of its popular uses and that no pharmacological studies has been carried out in these regards for 
$U$. circularis, the aim of this study was to evaluate its possible hypotensive and diuretic effects.

\section{MATERIALS AND METHODS}

\subsection{Plant Material}

U. circularis (Hicken) Sorarú was collected in Estancia "La Merced", Saladas Department, Corrientes, Argentina and identified by Dr Martha Gattuso. A voucher specimen (No. 054) is deposited in Facultad de Ciencias Químicas, Universidad Nacional de Rosario, Argentina.

\subsection{Extraction and Isolation}

The dried aerial parts of $U$. circularis were ground into a fine powder and extracted by maceration with $80 \%$ ethanol. The extract was concentrated and lyophilized (yield: $11.47 \%$, $\mathrm{w} / \mathrm{w})$. The extract was dissolved in saline solution for intraperitoneal (i.p.) or intravenous (i.v.) administration.

The HPLC method was developed, validated and performed with a Varian 9000 instrument using a diode array detector. A C18 column (Gemini 5 $\mu \mathrm{m}, 150 \times 4.6 \mathrm{~mm})$ was used. Solvent $A$ : $\mathrm{H}_{2} \mathrm{O} / \mathrm{AcOH}$ (98:2); solvent $\mathrm{B}: \mathrm{MeOH} / \mathrm{AcOH}$ (98:2). Gradient: $15 \%$ B to $40 \%$ B, $30 \mathrm{~min} ; 40 \%$ B to $75 \%$ B, $10 \mathrm{~min} ; 75 \%$ B to $85 \%$ B, 5 min. Flow rate: $1.2 \mathrm{~mL} / \mathrm{min}$. Detection: $325 \mathrm{~nm}$. A Rheodyne injector fitted with a $20 \mu \mathrm{L}$ loop was used. A major component of the extract was purified by preparative column chromatography in Sephadex LH20. The mobile phase was a gradient from $\mathrm{CH}_{2} \mathrm{Cl}_{2}(100 \%)$ to $\mathrm{MeOH}(100 \%)$. Afterward, preparative paper chromatography was performed on Whatman No. 3 using first $\mathrm{nBuOH}: \mathrm{AcOH}: \mathrm{H}_{2} \mathrm{O}, 4: 1: 1$ (twice), and then water as solvents. The purity of the isolated compound was checked by HPLC analysis and was $97 \%$ on the basis of peak area integration. It was identified as vicenin-2 (5,7,40-trihydroxyflavone 6,8-di-C-glucoside, $1, \quad 0.08 \% \quad \mathrm{w} / \mathrm{w})$ by spectroscopic data measurement (UV-VIS, $1 \mathrm{H}$ NMR, ESIMS) and by comparison with literature values [7].

\subsection{Animals}

Male Sprague-Dawley and hypertensive (SHR: Spontaneously Hypertensive Rat) rats (200-220 g) were used according to international guiding principles and local regulations concerning care and use of laboratory animals for biomedical research (NIH Publication № 85-
23, Revised 1985). Animals had free access to a standard commercial diet and water ad libitum and were kept in room maintained at $22 \pm 1^{\circ} \mathrm{C}$ with 12-h light/dark cycle. Experiments involving animals were approved by the Ethical Committee for the Care and Use of Laboratory Animals of School of Pharmacy and Biochemistry, Universidad de Buenos Aires (Ethics approval: Exp-FFyB 738657/11, Res 3438).

\subsection{Drugs}

Phenylephrine hydrochloride, indomethacin, LNG-Nitroarginine methyl ester, DPPH (2,2diphenyl-1-picrylhydrazyl) were purchased from Sigma (St. Louis, MO, USA). All chemicals used to prepare Krebs' solution were analytical grade and solubilized in distilled water.

Vicenin-2 was previously isolated from $U$. circularis [7]. The flavonoid solutions were prepared in dimethylsulfoxide (DMSO). The final concentration of DMSO was less than $0.05 \%$ which has been proven not to induce any observable effects on muscle tone. Indomethacin was dissolved in sodium bicarbonate $(0.5 \%)$. All other drugs and solutions were prepared and used immediately.

\subsection{In vivo Assays and Pharmacological Procedures}

\subsubsection{Evaluation of the effects of $U$. circularis on blood pressure of anaesthetized rats}

Sprague-Dawley and SHR were anaesthetized with pentobarbital $(40 \mathrm{mg} / \mathrm{kg}$, i.p.) and allowed to breathe spontaneously through a tracheal cannula. A polyethylene catheter (PE50) was inserted into the femoral vein and a bolus injection of heparin (300 IU) was immediately administered. This venous access was used for i.v. injections. Another catheter was inserted into the carotid artery and connected to a Statham Gould P23ID pressure transducer coupled to a Grass 79Dpolygraph. The mean arterial pressure (MAP) was calculated according to the following formula:

diastolic pressure + (systolic pressure diastolic pressure) / 3

The heart rate (HR) was estimated tachographically by counting the pulsatile waves of arterial pressure recordings. After the surgery, a 30 min interval was allowed for MAP stabilization. Rats received extracts (0.1-30 $\mathrm{mg} / \mathrm{kg})$ or isotonic saline $(0.1 \mathrm{~mL} / \mathrm{kg})$. Each dose 
of $U$. circularis extract was administered 20 min after the previous injection (this interval was enough to warrant that the MAP would be back to normal levels). The $U$. circularis extract was diluted from a stock solution in sterile isotonic saline immediately before its administration [14]. Nifedipine $(10 \mathrm{mg} / \mathrm{kg})$ was used as reference drug.

\subsubsection{Effect on urinary volume and sodium excretion}

Diuretic activity was determined according to the method previously described [15], but with some modifications. For these experiments, rats were divided into four groups $(n=4)$ and fasted overnight for eighteen hours before testing, with free access to tap water only. Before treatment (30 min), all animals received an overload of 2 $\mathrm{mL} / 100 \mathrm{~g}$ of water in an oral dose. Subsequently, rats were administered with extract $(100$ and $300 \mathrm{mg} / \mathrm{kg})$, furosemide $(10 \mathrm{mg} / \mathrm{kg})$ or saline solution by intraperitoneal route. Immediately after administration, the animals were placed in metabolic cages. Urine was collected in a graduated cylinder and its volume was measured and recorded 1, 2, 3, 4, 5 and $24 \mathrm{~h}$ after treatment. Cumulative urine excretion was calculated. Sodium and potassium concentration was estimated from each urine sample using indirect ion-selective electrode potentiometry and expressed as $\mathrm{mEq} / \mathrm{L}$. The diuretic index (mean urinary volume of test group/ mean urinary volume of control group), saluretic index (concentration of electrolyte in urine of the test group/ concentration of electrolyte in urine of control group) were calculated.

\subsection{In vitro Assays and Analytical Procedures}

\subsubsection{Preparation of rat aortic rings}

Aortic rings were prepared as previously described [16]. Briefly, segments of the thoracic aorta from rats were excised. After removing adhering tissue, aorta was cut into 4-mm long rings and transferred to a dish filled with Krebs' solution $(115.3 \mathrm{mM} \mathrm{NaCl}, 4.9 \mathrm{mM} \mathrm{KCl}, 1.46 \mathrm{mM}$ $\mathrm{CaCl}_{2} .2 \mathrm{H}_{2} \mathrm{O}, 1.2 \mathrm{mM} \mathrm{KH}_{2} \mathrm{PO}_{4}, 1.2 \mathrm{mM} \mathrm{MgSO}$, $11.1 \mathrm{mM}$ D-glucose, $25 \mathrm{mM} \mathrm{NaHCO} 3, \mathrm{pH}$ 7.4). Rings were suspended in organ baths containing Krebs' solution bubbled with a carbogenic mix $\left(5 \% \mathrm{CO}_{2} / 95 \% \mathrm{O}_{2}\right)$ at $37^{\circ} \mathrm{C}$. Isometric force transducers coupled to a Grass 79D polygraph were used to record contraction and relaxation.
Preparations were maintained at a basal tension of $2 \mathrm{~g}$ and allowed to stabilize for $1 \mathrm{~h}$ before addition of any drug. Control experiments, performed in the presence dimethylsulphoxide (DMSO) alone demonstrated that the solvent did not alter the contractile response of aortic rings. Endothelial integrity was verified by the ability of acetylcholine (1 $\mathrm{MM} \mathrm{ACh})$ to induce more than $70 \%$ of relaxation on pre-contracted vessels.

\subsubsection{Measurement of vascular relaxation and assessment of the mechanisms involved}

The evaluation of the ability of vicenin-2, extracted from $U$. circularis, to cause vascular relaxation was done in endotheliumintact aortic rings previously contracted by Phenylephrine (Phe) $(0.1 \mu \mathrm{M})$. Once the plateau was attained, under the sustained contraction, the vessels were exposed to cumulative concentrations of vicenin-2 $\left(10^{-7}-10^{-4} \mathrm{M}\right)$. In a separated set of experiments using endothelium-intact rings the same procedure was performed in preparations incubated for $20 \mathrm{~min}$ in the presence of L-NG-Nitro arginine methylester (L-NAME: $10 \mu \mathrm{M}$, a non-selective nitric oxide synthase inhibitor) and indomethacin (10 $\mu \mathrm{M}$, a non-selective cyclooxygenase inhibitor).

\subsubsection{Assessment of 2,2 diphenyl 2 picryl hydrazyl hydrate (DPPH) radical scavenging activity}

The scavenging activity of the extract and vicenin-2 on the stable free radical DPPH was assayed using the modified Blois' method [17], in which the bleaching rate of DPPH is monitored at a characteristic wavelength in presence of the sample. A volume of $0.1 \mathrm{~mL}$ of sample was mixed with $0.5 \mathrm{~mL}$ of a $500 \mu \mathrm{M}$ DPPH solution in methanol and $0.4 \mathrm{~mL}$ of a $0.1 \mathrm{M}$ Tris- $\mathrm{HCl}$ buffer, $\mathrm{pH}$ 7.4. The mixture was kept for $20 \mathrm{~min}$ in the dark and then the absorbance was read at 517 $\mathrm{nm}$. The percentage of decrease of DPPH absorbance was calculated by measuring the absorbance of the sample and applying the following equation:

$$
\% \text { of inhibition }=\left[1-\left(A_{s} / A_{0}\right)\right] \times 100
$$

where $A_{s}$ is absorbance of sample and $A_{0}$ is the absorbance of the DPPH solution. Ascorbic acid solutions of different concentrations were used as positive controls for antioxidant activity. 


\subsection{Statistical Analysis}

The pharmacological results are expressed as mean $\pm S E M$. Concentrations-response curves were plotted and experimental data were adjusted by a non-linear curve fitting program. Statistical analysis was performed by one-way analysis of variance (ANOVA), followed by Bonferroni or Dunnet' tests. $P<.05$ and $P<.01$ were considered to be statistically significant (GraphPad Prism5, version 5.03 for windows).

\section{RESULTS}

\subsection{Phytochemical Studies}

In order to analyze the ethanol extract used in this study, HPLC was performed. A major peak at $24.2 \mathrm{~min}$, was observed and it was identified as vicenin-2 by spectroscopic data measurement after isolation [7]. The corresponding fingerprint chromatogram is shown in Fig. 1.

\subsection{Effect on Arterial Pressure and Heart Frequency}

The i.v. administration of the extract of $U$. circularis $(0.1-30 \mathrm{mg} / \mathrm{kg})$ in anaesthetized normotensive and hypertensive (SHR) rats caused a dose-dependent reduction in the mean arterial pressure (MAP) without affecting the heart rate (HR) (Fig. 2). It is interesting to note that the greater reduction of blood pressure induced by $U$. circularis was observed in hypertensive rats $(30 \mathrm{mg} / \mathrm{kg}$ : SHR: $-34.7 \pm 3.3$ $\mathrm{mmHg}$, Spague Dawley: $-18.3 \pm 3.9 \mathrm{mmHg})$. A single administration of nifedipine $(10 \mathrm{mg} / \mathrm{kg})$, a reference agent, induced a hypotensive effect

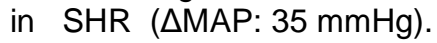

\subsection{Diuresis}

Intraperitoneal administration of the extract increased the urinary flow. The cumulative urinary excretions $24 \mathrm{~h}$ after treatment with the extract 100 and $300 \mathrm{mg} / \mathrm{kg}$ were $18.2 \pm 1.2$ and $14.9 \pm 1.5 \mathrm{~mL}$ respectively. These values were significantly higher $(P<.01)$ when compared to the control group $(9.0 \pm 1.3 \mathrm{~mL})$. Therefore, $U$. circularis 100 and $300 \mathrm{mg} / \mathrm{kg}$ led to a relative increase in cumulative diuresis of around $101 \%$ and $65 \%$, respectively, compared to the control group. Furthermore, the diuretic index values of the test groups were 1.91 and 1.61, which indicated a good diuretic activity in both doses. Meanwhile, reference drug group was 1.53. At dose of $300 \mathrm{mg} / \mathrm{kg}$ of extract the concentration of potassium and sodium excretions were similar compared to the furosemide treated group. The saluretic index values showed an increase in the excretion of $\mathrm{Na}^{+}$and $\mathrm{K}^{+}$only in the higher dose of extract and the reference drug group (Sodium: $U$. circularis $100 \mathrm{mg} / \mathrm{kg}$ : 0.99; U. circularis 300 $\mathrm{mg} / \mathrm{kg}$ : 1.61; furosemide $30 \mathrm{mg} / \mathrm{kg}$ : 1.44 ; Potasssium: $U$. circularis $100 \mathrm{mg} / \mathrm{kg}$ : 0.91; $U$. circularis $300 \mathrm{mg} / \mathrm{kg}$ : 1.56; furosemide 30 $\mathrm{mg} / \mathrm{kg}:$ 1.63) (Fig. 3).

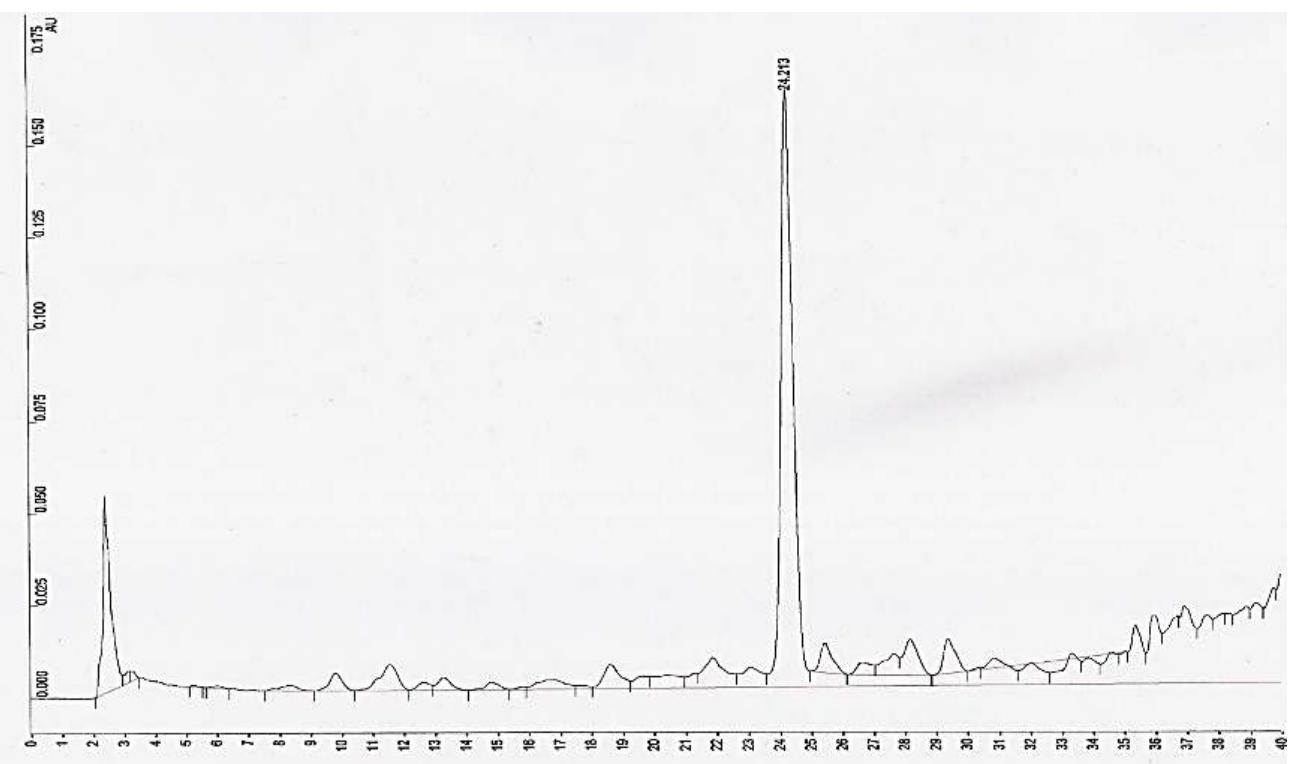

Fig. 1. HPLC Chromatogram of the ethanol extract of $U$. circularis 
A
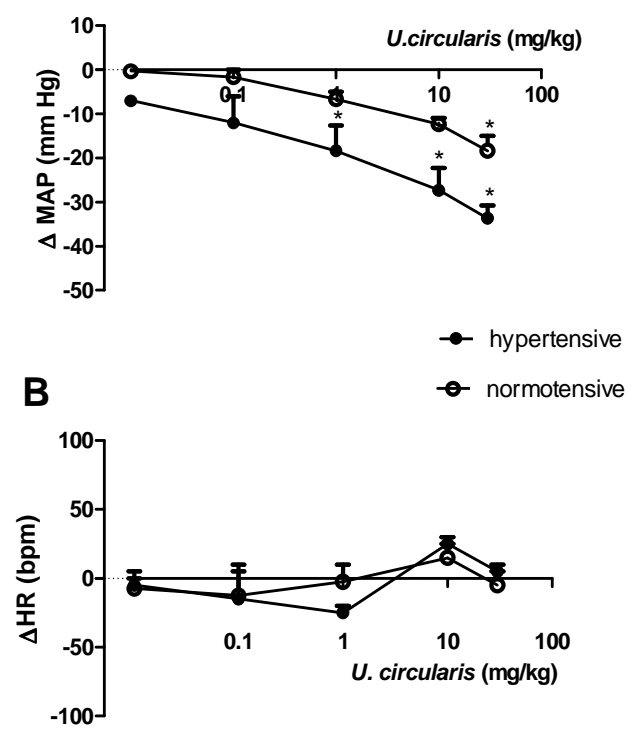

Fig. 2. Acute effect of the ethanol extract of U. circularis ( $\mathrm{mg} / \mathrm{kg}$ i.v.) on mean arterial pressure (A) and heart rate (B) in anaesthetized normotensive and spontaneously hypertensive (SHR) rats Values are expressed as mean $\pm S E M(n=5)$. ${ }^{*} P<.01$ versus basal measure (ANOVA)

\subsection{Effects of Vicenin-2 from $U$. circularis on Vascular Tonus}

The addition of cumulative concentrations of vicenin-2 $\left(10^{-7}-10^{-4} \mathrm{M}\right)$ generated relaxation in endothelium-intact aortic rings pre-contracted with $10^{-7} \mathrm{M}$ Phe $\left(\mathrm{E}_{\max }=66.2 \pm 3.5 \%\right)$. It was also found that the induced aortic relaxation by vicenin-2, was conserved after incubation with the indomethacin, but was reduced after incubation with L-NAME, suggesting nitric oxide pathway could be involved in its mechanism of action.

\subsection{Antioxidant Activity}

The scavenging activity of the extract and vicenin-2 was concentration dependent as shown in Fig. 5 (A, B) The results indicate that $U$. circularis's extract showed antioxidant activity reaching $45 \%$ of DPPH scavenging activity at $1000 \mu \mathrm{g} / \mathrm{mL}$, meanwhile the flavonoid reached $20 \%$ of scavenger capacity. The ascorbic acid (control antioxidant drug) was shown in Fig. 5C. and it is higher than extract and vicenin-2 at the same concentration.

\section{DISCUSSION}

The main finding of the present study is that the extract of $U$. circularis was able to reduce the blood pressure and induce a diuretic effect in rats, representing the first attempt to describe the pharmacological evidences of antihypertensive effect of this extract. The method used in this study for blood pressure measurement was extensively used in the screening of cardiovascular effect of drugs [18]. The observed acute hypotensive effect on normotensive rats indicates a direct action of its components on the cardiovascular system. Nevertheless, the extract does not seem to affect the capacity of the heart to increase heart rate in order to compensate after the initial hypotension. Moreover, taking into account that SHR animals presents similar aspects with essential hypertension in humans, including genetic susceptibility, gradual development, and end-organ damage [19], antihypertensive activity of the extract could be demonstrated.

The blood pressure is a product of cardiac output and vascular resistance and hypertension is associated with vascular functional and structural changes including endothelial dysfunction, so the in vivo activity of the extract could be related to its effect on blood vessels.

In this regard, the in vivo hypotensive property of $U$. circularis could be substantiated by in vitro investigation on the isolated aorta where the main compound showed vasorelaxant effect, suggesting that vicenin-2 could be responsible, at least in part of the activity of the extract. Also, endothelial nitric oxide, an important signaling molecule, could participate in the relaxation induced by the phytochemical. In agreement to our knowledge, this is the first time, that vicenin-2 showed this activity. It was described that this compound decreased acetylcholine or barium induced contraction on intestinal smooth muscle [20], and attenuated vascular permeability, monocyte adhesion, activation of nuclear factor NF-kB on high-glucose induced vascular inflammatory [21], but not the activity showed in this study. 

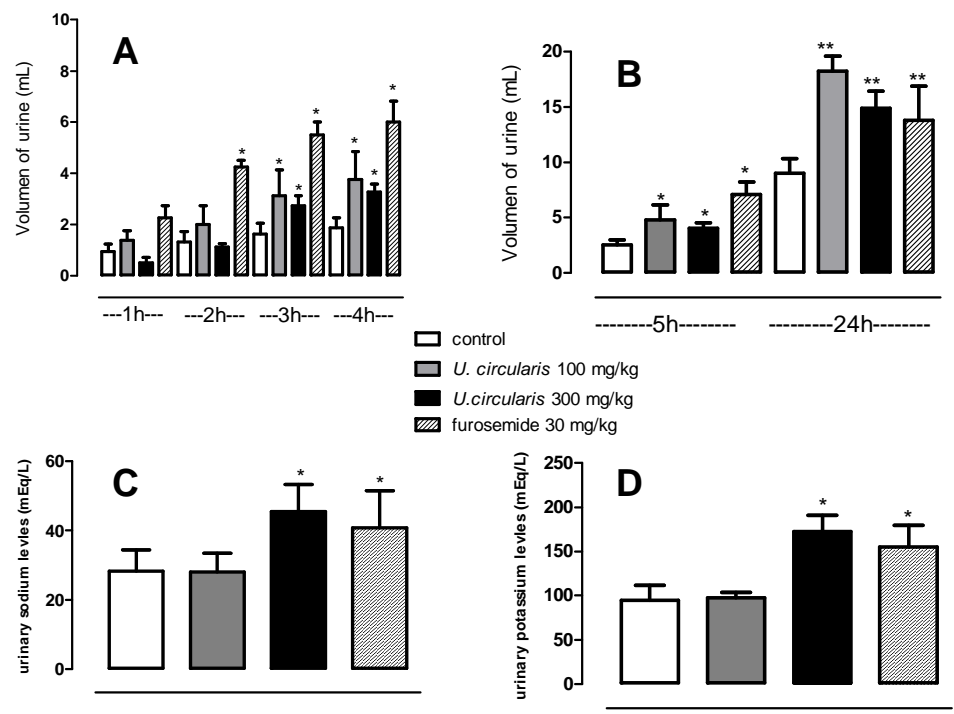

Fig. 3. Effect on urinary volume ( $A$ and $B$ ), sodium (C) and potassium (D) urinary levels of ethanol extract of $U$. circularis (100 and $300 \mathrm{mg} / \mathrm{kg}$ ), furosemide $(30 \mathrm{mg} / \mathrm{kg}$ ) and saline

Values are expressed as mean \pm SEM. $(n=5) .{ }^{*} P<.05$ and ${ }^{* *} P<.01$ versus control group (ANOVA, Bonferroni and Dunnett tests)

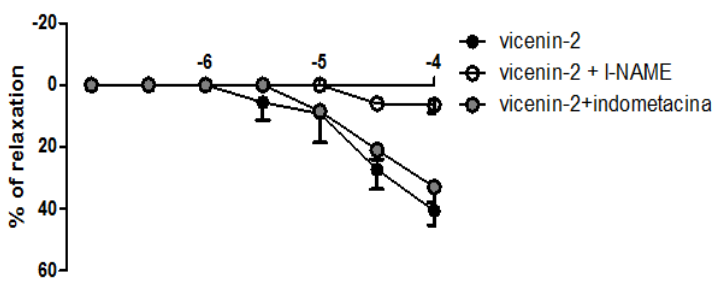

Fig. 4. Effect of L-NG-Nitro arginine methylester and indomethacin on the relaxation induced by vicenin- 2 in precontracted aortic rings

Values are expressed as mean \pm SEM. $(n=4)$

The association between cardiovascular disease and renal impairment is well established and important. Furthermore, taking into account that diuretics remain as the preferred drugs for initial treatment in many hypertensive patients and that previous studies have established the hypotensive and diuretic effect of other species of Urtica after intravenous injection [12], the renal effect of the extract was evaluated. U. circularis showed diuretic index values greater than 1.5 in rats, hence, it is considered that the extract has a good diuretic activity [22]. Significant increase in urinary volume was observed not up to $3 \mathrm{~h}$ after administration, suggesting a slight delayed action, in contrast to furosemide, which acts within a relatively short time. Rise in the excretion of urinary electrolytes such as sodium and potassium was observed only at the higher dose of extract. Most diuretics enlarge the excretion of sodium and potassium, the exception being potassium-sparing diuretics, which increase the excretion of sodium but conserve potassium. These observations suggest that the extract is not acting as potassium-sparing diuretics, although more studies must be necessary to clear the mechanisms involved in its diuretic effects.

Despite the diverse etiology of cardiovascular conditions, the enhanced production of ROS and altered oxygen utilization is apparently a common phenomenon and a participant in disease progression. Several antioxidants from natural sources have been proposed to prevent or reduce disease risk [23]. The DPPH method is widely used to test the ability of compounds to act as free radical scavengers or hydrogen donors, and to evaluate antioxidant capacity [24]. In this study, the extract and the main compound demonstrated free-radical-scavenging activity. Nevertheless, this activity was found to be lower than that of the reference natural antioxidant, ascorbic acid. But it is important to remark that since the oxidative stress leads to endothelial dysfunction by reducing NO bioavailability, the antioxidant activity of the extract and its main compound could collaborate in the beneficial activities on blood vessel observed in this work. 


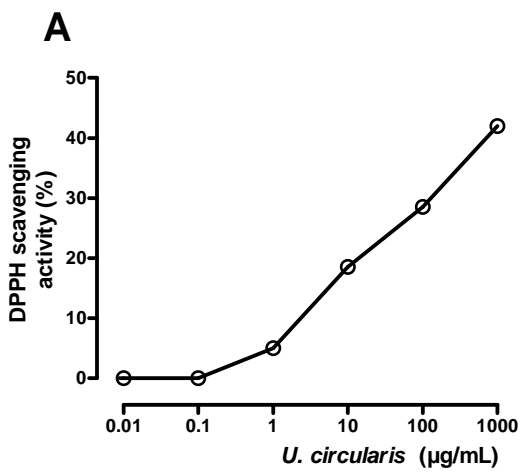

B
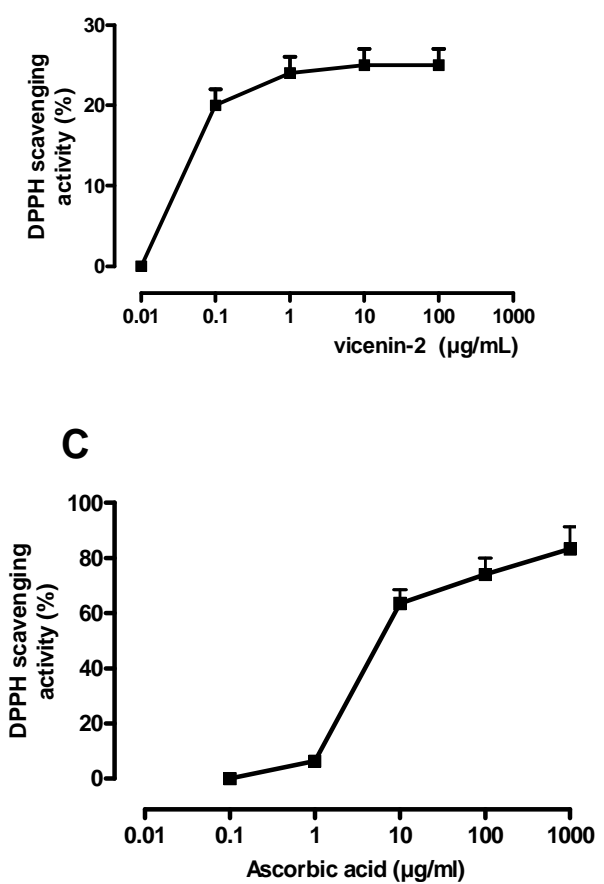

Fig. 5. DPPH scavenging activity of $U$. circularis extract $(A)$, vicenin-2 (B) and ascorbic acid (C)

Even though several medicinal plants have been described as promising hypotensive and diuretic agents like Artemisia copa, Artemisia herba alba, and other species of Urtica such as U. dioica $[16,18,25]$, this is the first time that this ability was demonstrated by $U$. circularis. Furthermore this activity may be associated, at least in part, with the presence of vicenin-2 found in this plant.

\section{CONCLUSION}

The results of the present study demonstrate that the ethanol extract of $U$. circularis, has a diuretic, antioxidant and hypotensive effect. As vicenin-2 is the major component of this extract, this compound is potentially responsible for these properties. Vicenin-2 proved to possess vasorelaxant activity, through its effect on endothelial NOS.

The effects showed in the present study supports the ethnomedical use of this plant and contributes to the scientific knowledge of the properties of our medicinal flora. And it could explain its folkloric repute as antihypertensive agent.

\section{CONSENT}

It is not applicable.

\section{ACKNOWLEDGEMENT}

This work was supported by Grants from Universidad de Buenos Aires (UBACyT 20020130200265BA).

\section{COMPETING INTERESTS}

Authors have declared that no competing interests exist.

\section{REFERENCES}

1. WHO. Monographs on selected medicinal plants. 2004;2:329-41.

2. Baradaran A, Nasri H, Rafieian-Kopaei M. Oxidative stress and hypertension: Possibility of hypertension therapy with antioxidants. J Res Med Sci. 2014;19(4): 358-67.

3. Burkart A. Flora ilustrada de entre ríos. Sudamericana, Buenos Aires; 1987. (Spanish)

4. Rondina R, Bandoni A, Coussio J. Plantas silvestres argentinas con reconocidas propiedades medicinales 0 tóxicas. segunda edición (CD-ROM). CYTED (Ciencia y Tecnología para el Desarrollo). Buenos Aires; 2003. (Spanish)

5. Del Vitto L, Petenatti E, Petenatti M. Recursos herbolarios de San Luis (República Argentina) Primera parte: Plantas nativas. Multequina. 1997;6: 49-66. (Spanish)

6. Martínez Crovetto R. Plantas utilizadas en medicina en el noroeste de corrientes. miscelanea (Fundación Miguel Lillo), Tucumán; 1981. (Spanish) 
7. Marrassini C, Davicino $\mathrm{R}$, Acevedo $\mathrm{C}$, Anesini C, Gorzalczany S, Ferraro G. Vicenin-2, a potential anti-inflammatory constituent of Urtica circularis. J Nat Prod. 2011;74(6):1503-7.

8. Gorzalczany S, Marrassini C, Miño J, Acevedo C, Ferraro G. Antinociceptive activity of ethanolic extract and isolated compounds of Urtica circularis. J Ethnopharmacol. 2011;134(3):733-8.

9. Anzoise ML, Marrassini C, Ferraro G, Gorzalczany S. Hydroalcoholic extract of Urtica circularis: A neuropharmacological profile. Pharm Biol. 2013;51(10):1236-42.

10. European Medicines Agency (EMEA). Evaluation of medicines for human use. Assessment Report on Urtica dioica L. and Urtica urens L. Herba. Doc. Ref. EMEA/ HMPC/168380/2006; London. 2008;1-26.

11. List of German Commission $E$ Monographs (Phytotherapy); 1987.

Available:http://buecher.heilpflanzenwelt.de/BGA-Commission-E-

Monographs/0349.htm

(Accessed 09 September 2015)

12. Tahri A, Yamani S, Legssyer A, Aziz M, Mekhfi $\mathrm{H}$, Bnouham $M$, et al. Acute diuretic, natriuretic and hypotensive effects of a continuous perfusion of aqueous extract of Urtica dioica in the rat. J Ethnopharmacol. 2000;73(1-2):95-100.

13. Testai L, Chericoni S, Calderone V, Nencioni G, Nieri P, Morelli I, et al. Cardiovascular effects of Urtica dioica $\mathrm{L}$. (Urticaceae) roots extracts: in vitro and in vivo pharmacological studies. J Ethnopharmacol. 2002;81(1):105-109.

14. Rattmann Y, Crestani S, Lapa F, Miguel O, Marques $M$, daSilva- Santos $J$, et al. Activation of muscarinic receptors by a hydroalcoholic extract of Dicksonia sellowiana Presl. HooK (Dicksoniaceae) induces vascular relaxation and hypotension in rats. Vascul Pharmacol. 2009;50:27-33.

15. Kau S, Keddi J, Andrews D. A method for screening diuretic agents in rats. $J$ Pharmacol Method. 1984:11:67-75.
16. Gorzalczany S, Moscatelli V, Ferraro G. Artemisia copa aqueous extract as vasorelaxant and hypotensive agent. J Ethnopharmacol. 2013;148:56-61.

17. Blois M. Antioxidant determinations by the use of a stable free radical. Nature. 1958; 181:1199-1200.

18. Zeggwagh N, Michel J, Eddouks M. Acute hypotensive and diuretic activities of Artemisia herba alba aqueous extract in normal rats. Asian Pac J Trop Biomed. 2014;4(2):S644-8.

19. Pinto $Y$, Paul M, Ganten D. Lessons from rat models of hypertension: From goldblatt to genetic engineering. Cardiovasc Res. 1988;39(1):77-88.

20. Verspohl E, Fujii H, Homma K, BuchwaldWerner S. Testing of Perilla frutescens extract and Vicenin-2 for their antispasmodic effect. Phytomedicine. 2013;20(5):427-31.

21. Ku S, Bae J. Vicenin-2 and scolymoside inhibit high-glucose-induced vascular inflammation in vitro and in vivo. Can J Physiol Pharmacol. 2016;94(3):28795.

22. Asif $M$, Jabeen $Q$, Majid $A$, Atif $M$. Diuretic activity of aqueous extract of Nigella sativa in albino rats. Acta Pol. Pharm. Drug Research. 2015;72(1):12935.

23. Wattanapitayakula S, Bauer J. Oxidative pathways in cardiovascular disease roles, mechanisms, and therapeutic implications. Pharmacol Ther. 2001;89(2):187-206.

24. Karagöz A, Artun F, Özcan G, Melikoğlu G, Anıl S, Kültür $S$, et al. In vitro evaluation of antioxidant activity of some plant methanol extract. Biotechnol. Biotechnol. Equip. 2015;29(6):1184-9.

25. Kazama C, Uchida D, Canzi K, de Souza P, Crestani S, Gasparotto A, Laverde A. Involvement of arginine-vasopressin in the diuretic and hypotensive effects of Pereskia grandifolia Haw. (Cactaceae). J Ethnopharmacol. 2012;144:86-93.

(c) 2016 Basso et al.; This is an Open Access article distributed under the terms of the Creative Commons Attribution License (http://creativecommons.org/licenses/by/4.0), which permits unrestricted use, distribution, and reproduction in any medium, provided the original work is properly cited.

Peer-review history:

The peer review history for this paper can be accessed here: http://sciencedomain.org/review-history/14180 